\title{
Mid-infrared emission and quantitative analysis of energy transfer processes in $\mathrm{Er}^{3+}$ doped oxyfluogermanate glasses
}

\author{
Muzhi Cai, Beier Zhou, Fengchao Wang, Ying Tian, Jiajia Zhou, Shiqing $\mathrm{Xu},{ }^{\text {a) }}$ \\ and Junjie Zhang ${ }^{\text {a) }}$ \\ College of Materials Science and Engineering, China Jiliang University, Hangzhou 310018, \\ People's Republic of China
}

(Received 24 April 2015; accepted 16 June 2015; published online 26 June 2015)

\begin{abstract}
Oxyfluogermanate glasses with good thermal stability were prepared by melt-quenching method. The investigation of $2.7 \mu \mathrm{m}$ fluorescence spectra and energy transfer mechanism was performed pumped by an $808 \mathrm{~nm}$ laser diode. The $2.7 \mu \mathrm{m}$ radiative transition probability and emission cross section are $32.62 \mathrm{~s}^{-1}$ and $12.88 \times 10^{-21} \mathrm{~cm}^{2}$, respectively. The energy transfer parameters between ${ }^{4} \mathrm{I}_{11 / 2}$ and ${ }^{4} \mathrm{I}_{13 / 2}$ levels were calculated by Inokuti-Hirayama and Yokota-Tanimoto's model to further elucidate $2.7 \mu \mathrm{m}$ fluorescent behaviors. It is found that the energy transfer mechanism among $\mathrm{Er}^{3+}$ is mainly dominated by dipole-dipole interactions. Results indicate that the prepared oxyfluogermanate glass is a promising candidate for mid-infrared laser applications. (C) 2015 AIP Publishing LLC. [http://dx.doi.org/10.1063/1.4923064]
\end{abstract}

\section{INTRODUCTION}

The mid-infrared (MIR) wavelength range $(2-5 \mu \mathrm{m})$, which covers important atmospheric windows, has drawn significant interests in the last decades because of the potential applications in civil and military fields. ${ }^{1-3}$ To achieve efficient MIR emission, an appropriate host material and rare earth ions should be considered carefully. Rare earth ions for MIR emissions are mainly focused on $\mathrm{Er}^{3+}, \mathrm{Ho}^{3+}, \mathrm{Dy}^{3+}$, and $\mathrm{Pr}^{3+}$ (Refs. 4-7) to date. Among them, $\mathrm{Er}^{3+}$ is deemed as an ideal candidate since it is capable of generating $2.7 \mu \mathrm{m}$ luminescence via the ${ }^{4} \mathrm{I}_{11 / 2} \rightarrow{ }^{4} \mathrm{I}_{13 / 2}$ transition. Moreover, it is conveniently pumped by commercially available $808 \mathrm{~nm}$ or $980 \mathrm{~nm}$ laser diodes. On the other hand, the host has an important influence on the $2.7 \mu \mathrm{m}$ emission. Last decades have witnessed the great development of mid-infrared materials such as crystal and glass. ${ }^{6,8}$ Compared with crystal, glass has the merits of high solubility in rare earth ions and low cost. Up to now, many different kinds of glass have been investigated for mid-infrared applications including chalcogenide, fluoride, and heavy metal oxide glasses. ${ }^{8-12}$ Although chalcogenide glass have quite low phonon energy and larger refractive index, it is difficult to draw into fiber due to its relatively low recrystallisation temperature which is close to the fiber drawing temperature. ${ }^{13}$ Fluoride glass or fiber is a natural candidate as mid-infrared laser owing to its low phonon energy and superior infrared transmittance performance. ${ }^{14}$ Based on this idea, in 2011, a maximum output power of $20.6 \mathrm{~W}$ at $2.825 \mu \mathrm{m}$ was achieved from $\mathrm{Er}^{3+}$ doped fluoride fiber and the slope efficiency of the passively cooled laser was up to $35.4 \% .{ }^{15}$ In 2013, single-longitudinal-mode fiber laser operating at $2914 \mathrm{~nm}$ was demonstrated in $\mathrm{Ho}^{3+}$ / $\mathrm{Pr}^{3+}$ codoped ZBLAN fiber with a spectrometer-limited linewidth of $<0.4 \mathrm{~nm}$ when pumped at $1150 \mathrm{~nm} .{ }^{16}$ In addition, $\mathrm{Dy}^{3+}$ doped ZBLAN fiber laser operating at $2.96 \mu \mathrm{m}$ was

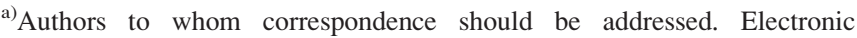
addresses: jjzhang@cjlu.edu.cn and shiqingxu@cjlu.edu.cn
}

also determined by $\sim 1.3 \mu \mathrm{m} \mathrm{Nd}$ : YAG laser pumping. ${ }^{17}$ Unfortunately, fluoride glass has the disadvantages of poor thermal stability, chemical durability, and mechanical strength. $^{14}$

Heavy metal oxide glass has lower phonon energy than other oxide glasses (e.g., silicate and phosphate glasses) and better physicochemical stability than fluoride glass. Among heavy metal oxide glass, germanate glass is quite suitable as host material for mid-infrared laser contribution to the merits of excellent thermal stability, chemical durability, low maximum phonon energy, and high transparency in a wide wavelength region. ${ }^{18}$ Due to a high concentration of hydroxyl groups might lead to a strong absorption band around $2.7 \mu \mathrm{m}$, which is harmful for corresponding mid-infrared emission, in recent years, $\mathrm{BaF}_{2}$ and $\mathrm{LiF}$ additions are introduced to germanate glass to modify glass forming ability, and $\mathrm{F}^{-}$ions in glass can minimize the contents of hydroxyl groups and phonon energy. ${ }^{19}$

In this work, oxyfluogermanate glasses were prepared and mid-infrared fluorescence properties were investigated pumped by an $808 \mathrm{~nm}$ laser diode. $975 \mathrm{~nm}$ and $1530 \mathrm{~nm}$ emission spectra and corresponding decay lifetimes were determined to elucidate $2.7 \mu \mathrm{m}$ emission behaviors. Energy transfer parameters were also evaluated via InokutiHirayama and Yokota-Tanimoto's models.

\section{EXPERIMENTAL PROCEDURE}

\section{A. Sample preparation}

Oxyfluogermanate glasses have the compositions of $87\left(\mathrm{GeO}_{2}+\mathrm{Ga}_{2} \mathrm{O}_{3}+\mathrm{La}_{2} \mathrm{O}_{3}\right)-13\left(\mathrm{BaF}_{2}+\mathrm{LiF}\right)-1 \mathrm{Er}_{2} \mathrm{O}_{3}$ and $81\left(\mathrm{GeO}_{2}+\mathrm{Ga}_{2} \mathrm{O}_{3}+\mathrm{La}_{2} \mathrm{O}_{3}\right)-19\left(\mathrm{BaF}_{2}+\mathrm{LiF}\right)-1 \mathrm{Er}_{2} \mathrm{O}_{3}(\mathrm{~mol} . \%)$, denoted as FG-01 and FG-02, respectively. Powders of highpurity $\mathrm{GeO}_{2}, \mathrm{Ga}_{2} \mathrm{O}_{3}, \mathrm{BaF}_{2}, \mathrm{La}_{2} \mathrm{O}_{3}, \mathrm{LiF}$, and $\mathrm{Er}_{2} \mathrm{O}_{3}$ were used as raw materials. Well-mixed $20 \mathrm{~g}$ batches of the sample were placed in a high-purity $\mathrm{Al}_{2} \mathrm{O}_{3}$ crucible and melted in a Si-Mo resistance furnace at $1400{ }^{\circ} \mathrm{C}$ for $40 \mathrm{~min}$. Then, they 
quenched on preheated stainless steel plate and annealed near the temperature of glass transition for $2 \mathrm{~h}$ before they were cooled to room temperature. The annealed samples were finally cut and optically polished to the size of $20 \mathrm{~mm}$ $\times 10 \mathrm{~mm} \times 1.5 \mathrm{~mm}$ for the optical property measurements.

\section{B. Performance measurements}

The densities of samples were tested via the Archimedes principle using distilled water as the immersion medium with error of $\pm 0.001 \mathrm{~g} / \mathrm{cm}^{3}$. Refractive indexes were measured by the prism minimum deviation method at the wavelength of $1053 \mathrm{~nm}$ with error limit of $\pm 0.05 \%$. Differential scanning calorimeter (DSC) curves were measured using NETZSCH DTA $404 \mathrm{PC}$ at the heating rate of $10 \mathrm{~K} / \mathrm{min}$ with error of $\pm 5^{\circ} \mathrm{C}$. The characteristic temperatures (including temperatures of glass transformation, onset crystalline peak, and top crystalline peak) were determined by doing tangent at glass transformation point, near crystallization peak temperature, and top crystalline peak, respectively. Absorption spectra were obtained using a Perkin Elmer Lambda 900UVVIS-NIR spectrophotometer in the range of $350-1640 \mathrm{~nm}$ with a resolution of $1 \mathrm{~nm}$. Fluorescence spectra from 940 to $2800 \mathrm{~nm}$ were tested with a computer-controlled Triax 320 type spectrometer excited by an $808 \mathrm{~nm}$ laser diode. Excitation source with the same power was used to measure the fluorescence lifetimes of ${ }^{4} \mathrm{I}_{11 / 2}$ and ${ }^{4} \mathrm{I}_{13 / 2}$ level, which was recorded via HP546800B 100-MHz oscilloscope. The same experimental conditions for different samples were maintained so as to get comparable results. All the measurements were carried out at room temperature.

\section{RESULTS AND DISCUSSION}

\section{A. Thermal stability analysis}

Fig. 1 shows the DSC curves of oxyfluogermanate glasses. According to the thermal analysis, characteristic temperatures including temperatures of glass transition $\left(\mathrm{T}_{\mathrm{g}}\right)$, onset crystallization peak $\left(\mathrm{T}_{\mathrm{x}}\right)$, and top crystallization peak $\left(T_{p}\right)$ are obtained as assigned in Fig. 1. Table I summarizes $\mathrm{T}_{\mathrm{g}}, \mathrm{T}_{\mathrm{x}}, \mathrm{T}_{\mathrm{p}}$, thermal stability parameters $\Delta \mathrm{T}\left(\mathrm{T}_{\mathrm{x}}-\mathrm{T}_{\mathrm{g}}\right)$, and $\mathrm{S}$ in various glass hosts. Glass forming ability criterion, $\Delta \mathrm{T}$, has been frequently utilized to measure the glass stability and a

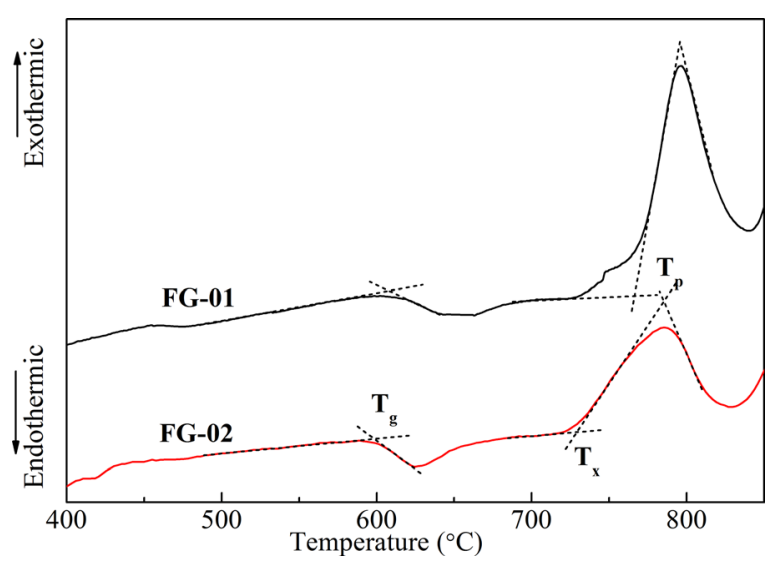

FIG. 1. DSC curves of oxyfluogermanate glasses.
TABLE I. The glass transition temperature $\left(\mathrm{T}_{\mathrm{g}}\right)$, onset crystallization temperature $\left(\mathrm{T}_{\mathrm{x}}\right)$, top crystallization peak $\left(\mathrm{T}_{\mathrm{p}}\right)$, thermal stability parameters $\Delta \mathrm{T}$ and $\mathrm{S}$ in various glass hosts.

\begin{tabular}{lcccccc}
\hline \hline Glass samples & $\begin{array}{c}\mathrm{T}_{\mathrm{g}} \\
\left({ }^{\circ} \mathrm{C}\right)\end{array}$ & $\begin{array}{c}\mathrm{T}_{\mathrm{x}} \\
\left({ }^{\circ} \mathrm{C}\right)\end{array}$ & $\begin{array}{c}\mathrm{T}_{\mathrm{p}} \\
\left({ }^{\circ} \mathrm{C}\right)\end{array}$ & $\begin{array}{c}\Delta \mathrm{T} \\
\left({ }^{\circ} \mathrm{C}\right)\end{array}$ & $\begin{array}{c}\mathrm{S} \\
(\mathrm{K})\end{array}$ & References \\
\hline FG-01 & 608 & 766 & 796 & 158 & 5.38 & This study \\
FG-02 & 599 & 729 & 786 & 130 & 8.50 & \\
Germanate & 618 & 747 & 769 & 129 & 4.59 & 12 \\
Bismuthate & 370 & 511 & 527 & 141 & 3.51 & 8 \\
Fluorophosphate & 462 & 549 & 565 & 87 & 1.89 & 10 \\
\hline \hline
\end{tabular}

large $\Delta \mathrm{T}$ means strong inhibition of nucleation and crystallization. The $\Delta \mathrm{T}$ of FG-01 and FG-02 glasses are calculated to be $158^{\circ} \mathrm{C}$ and $130^{\circ} \mathrm{C}$, respectively. They are higher than that of fluorophosphate glass, ${ }^{14}$ while comparable to those of bismuthate and germanate glasses. ${ }^{8,12}$

The parameter $\mathrm{S}$ is more accurate to estimate the glass stability, which reflects the resistance to devitrification after the formation of the glass and can be defined by

$$
S=\frac{\Delta T \times\left(T_{p}-T_{x}\right)}{T_{g}},
$$

where $\left(T_{p}-T_{x}\right)$ is related to the rate of devitrification transformation of the glassy phases. On the other hand, the high value of $\Delta \mathrm{T}$ delays the nucleation process. It is found that the $\mathrm{S}$ is $5.38 \mathrm{~K}$ and $8.50 \mathrm{~K}$ for FG-01 and FG-02, respectively. They are higher than those of bismuthate and fluorophosphate glass, while comparable to other germanate glass as shown in Table I.

Besides, a high $\mathrm{T}_{\mathrm{g}}$ is beneficial to minimize the thermal damage when pumped by high power lasers. ${ }^{12}$ It is found that the prepared samples possess a higher $\mathrm{T}_{\mathrm{g}}$ compared with other glasses. Hence, oxyfluogermanate glasses with good thermal stability might be selected as laser materials.

\section{B. Absorption spectra and Judd-Ofelt analysis}

Fig. 2 indicates absorption spectra of oxyfluogermanate glasses at room temperature in the wavelength region of $350-1640 \mathrm{~nm}$. Each absorption band corresponding to transitions from their ground state ${ }^{4} \mathrm{I}_{15 / 2}$ to higher levels ${ }^{4} \mathrm{I}_{13 / 2}$,

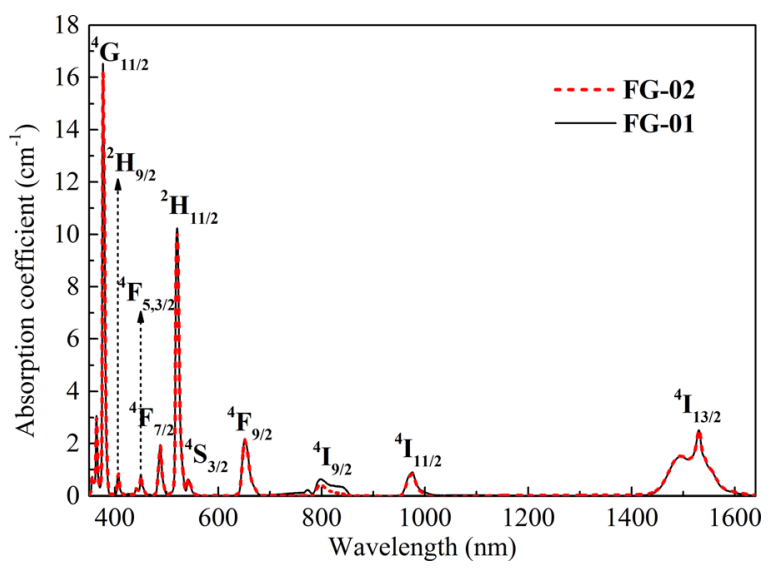

FIG. 2. Absorption spectra in $\mathrm{Er}^{3+}$ doped oxyfluogermanate glasses. 
${ }^{4} \mathrm{I}_{11 / 2},{ }^{4} \mathrm{I}_{9 / 2},{ }^{4} \mathrm{~F}_{9 / 2},{ }^{4} \mathrm{~S}_{3 / 2},{ }^{2} \mathrm{H}_{11 / 2},{ }^{4} \mathrm{~F}_{7 / 2},{ }^{4} \mathrm{~F}_{5 / 2}+{ }^{4} \mathrm{~F}_{3 / 2},{ }^{2} \mathrm{H}_{9 / 2}$, and ${ }^{4} \mathrm{G}_{11 / 2}$ is labeled. It is observed from Fig. 2 that the shape and peak positions of each transition are very similar in comparison to other $\mathrm{Er}^{3+}$ doped systems. ${ }^{20,21}$ Some tiny divergences can be found originated from various ligand field strength of glass. Compared with other transitions, ${ }^{4} \mathrm{I}_{15 / 2}$ $\rightarrow{ }^{4} \mathrm{G}_{11 / 2}$ and ${ }^{4} \mathrm{I}_{15 / 2} \rightarrow{ }^{2} \mathrm{H}_{11 / 2}$ transitions possess higher absorption coefficients, which are well-known hypersensitive transitions. They are sensitive to small changes of local environment around $\mathrm{Er}^{3+}$ ions. ${ }^{22}$ In addition, the absorption band around $808 \mathrm{~nm}$ signifies that the prepared glasses can be pumped by commercially available $808 \mathrm{~nm}$ laser diode.

According to Judd-Ofelt (J-O) theory, intensity parameters $\Omega_{2,4,6}$ have been calculated from absorption spectra. ${ }^{23,24}$ Table II lists J-O intensity parameters $\left(\Omega_{2,4,6}\right)$ and root mean square deviation $\left(\delta_{\text {r.m.s }}\right)$ of $\mathrm{Er}^{3+}$ in various glasses. It can be determined that $\delta_{\text {r.m.s }}$ in our samples are as low as $0.35 \times 10^{-6}$ and $0.12 \times 10^{-6}$, respectively, indicating that the reliability and validity of the calculated J-O intensity parameters. $\Omega_{\lambda}$ are useful parameters for the investigation of the local structure and bonding in the vicinity of $\mathrm{Er}^{3+}$ ions. It has been reported that $\Omega_{2}$ is sensitive to the environmental configuration symmetry of $\mathrm{Er}^{3+}$ ions and the amount of the covalent bonding. ${ }^{25} \mathrm{It}$ is observed that the $\Omega_{2}$ of the prepared samples are lower than those of tellurite, bismuth-germanate, and other germanate glasses as shown in Table II. Results demonstrate that oxyfluogermanate glasses possess lower covalency of bonding and asymmetry of ligand environment surrounding $\mathrm{Er}^{3+}$ ions.

Based on J-O intensity parameters, the spontaneous radiative transition probability $\left(\mathrm{A}_{\mathrm{rad}}\right)$ for $\mathrm{Er}^{3+}:{ }^{4} \mathrm{I}_{11 / 2} \rightarrow{ }^{4} \mathrm{I}_{13 / 2}$ transition has been calculated and the $A_{\text {rad }}$ is as high as $32.62 \mathrm{~s}^{-1}$, which is larger than those of ZBLA $\left(19 \mathrm{~s}^{-1}\right)$ and fluoride glass $\left(29.04 \mathrm{~s}^{-1}\right),{ }^{9}$ while comparable to that of YAG $\left(33 \mathrm{~s}^{-1}\right){ }^{9}$ High spontaneous transition probability is beneficial for high gain and more opportunity to achieve laser action. $^{29}$

\section{Fluorescence spectra and energy transfer mechanism}

Fig. 2(a) indicates mid-infrared fluorescence spectra of FG-01 and FG-02 samples at the excitation of $808 \mathrm{~nm}$ laser diode. The emission peaks at $2.7 \mu \mathrm{m}$ corresponding to the transition of ${ }^{4} \mathrm{I}_{11 / 2} \rightarrow{ }^{4} \mathrm{I}_{13 / 2}$ can be observed clearly. Moreover, the peak intensity of FG-02 is larger than that of FG-01. Fig. 2(b) shows the energy level diagram and energy transfer processes of $\mathrm{Er}^{3+}$ ions. It can be noted that the ions in ground state are populated to higher level ${ }^{4} \mathrm{I}_{9 / 2}$ at $808 \mathrm{~nm}$ pumping. Subsequently, populations in ${ }^{4} \mathrm{I}_{9 / 2}$ level relax to the lower ${ }^{4} \mathrm{I}_{11 / 2}$ level, quickly, owing to small energy gap between them. Afterwards, the ions in ${ }^{4} \mathrm{I}_{11 / 2}$ level decay radiatively to the ground state generating $975 \mathrm{~nm}$ emissions or radiatively relax to the ${ }^{4} \mathrm{I}_{13 / 2}$ level with $2.7 \mu$ m fluorescence. The ions in ${ }^{4} \mathrm{I}_{13 / 2}$ level decay radiatively to the ground state and $1.53 \mu \mathrm{m}$ emissions take place.

Evidently, the population evolution between ${ }^{4} \mathrm{I}_{11 / 2}$ and ${ }^{4} \mathrm{I}_{13 / 2}$ levels has an influence on $2.7 \mu \mathrm{m}$ fluorescence. Thus, it is necessary to investigate the emission spectra and lifetimes of ${ }^{4} \mathrm{I}_{11 / 2}$ and ${ }^{4} \mathrm{I}_{13 / 2}$ levels. Figs. 3(a) and 3(b) display the $975 \mathrm{~nm}$ and $1.53 \mu \mathrm{m}$ fluorescence spectra, respectively. It is clear that the $975 \mathrm{~nm}$ emission due to ${ }^{4} \mathrm{I}_{11 / 2} \rightarrow{ }^{4} \mathrm{I}_{15 / 2}$ transition can be observed and the intensity of FG-02 sample is weaker than that of FG-01 sample. The strength of ${ }^{4} \mathrm{I}_{11 / 2}$ $\rightarrow{ }^{4} \mathrm{I}_{13 / 2}$ transition can compete with that of ${ }^{4} \mathrm{I}_{11 / 2} \rightarrow{ }^{4} \mathrm{I}_{15 / 2}$ transition, so weak intensity of $975 \mathrm{~nm}$ emission is favorable for $2.7 \mu \mathrm{m}$ emission. It is also observed from Fig. 3(b) that $1.53 \mu \mathrm{m}$ fluorescence intensity of FG-02 sample is weaker than that of FG-01 sample. Weak $1.53 \mu \mathrm{m}$ emission may be due to the reduced populations of ${ }^{4} \mathrm{I}_{13 / 2}$ level, which is beneficial for population inversion between ${ }^{4} \mathrm{I}_{11 / 2}$ and ${ }^{4} \mathrm{I}_{13 / 2}$ level. Hence, $2.7 \mu \mathrm{m}$ emission intensity of FG-02 sample is higher than that of FG-01 sample.

$975 \mathrm{~nm}$ and $1.53 \mu \mathrm{m}$ fluorescent lifetimes are important parameters to estimate population evolution of ${ }^{4} \mathrm{I}_{11 / 2}$ and ${ }^{4} \mathrm{I}_{13 / 2}$ levels. According to the measured decay data, energy transfer parameter can be determined to analyze quantitatively energy transfer processes such as energy transfer upconversion (ETU1 and ETU2) as shown in Fig. 4(b).

Inokuti-Hirayama's (I-H) model can be utilized to evaluate the energy transfer processes among $\mathrm{Er}^{3+}$ ions, which is expressed as

$$
\frac{I(t)}{I(0)}=\exp \left(-\frac{t}{\tau_{0}}-Q\left(\frac{t}{\tau_{0}}\right)^{3 / S}\right),
$$

where $S$ is 6,8 , or 10 depending on whether the dominant mechanism of interaction is dipole-dipole, dipole-quadrupole, or quadrupole-quadrupole, respectively. $\tau_{0}$ is the intrinsic lifetime. The energy transfer parameter $(\mathrm{Q})$ is defined as

$$
Q=\frac{4 \pi}{3} \Gamma\left(1-\frac{3}{S}\right) N_{E r} R_{c}^{3}
$$

where $\Gamma(1-3 / \mathrm{S})$ is equal to 1.77 for dipole-dipole interactions $(S=6), 1.43$ for dipole-quadrupole interactions $(S=8)$, and 1.3 in the case of quadrupole-quadrupole interactions $(\mathrm{S}=10) . \mathrm{N}_{\mathrm{Er}}$ is the concentration of $\mathrm{Er}^{3+}$ ions (in ions $\mathrm{cm}^{-3}$ )

TABLE II. The J-O intensity parameters $\left(\times 10^{-20} \mathrm{~cm}^{2}\right)$ and root mean square deviation $\left(\times 10^{-6}\right)$ of $\mathrm{Er}^{3+}$ in various glasses.

\begin{tabular}{lccccc}
\hline \hline Glass samples & $\Omega_{2}$ & $\Omega_{4}$ & $\Omega_{6}$ & $\delta_{\text {r.m.s }}$ & References \\
\hline FG-01 & $4.71 \pm 0.01$ & $2.04 \pm 0.04$ & $0.82 \pm 0.03$ & 0.35 & Present work \\
FG-02 & $4.67 \pm 0.02$ & $1.84 \pm 0.03$ & $0.92 \pm 0.02$ & 0.12 & $\ldots$ \\
Bismuth-germanate & 5.57 & 2.49 & 4.53 & 1.90 & 0.47 \\
Germanate & 6.59 & 2.77 & 1.01 & $\ldots$ & 26 \\
Tellurite & 8.47 & 1.72 & 28 \\
\hline \hline
\end{tabular}



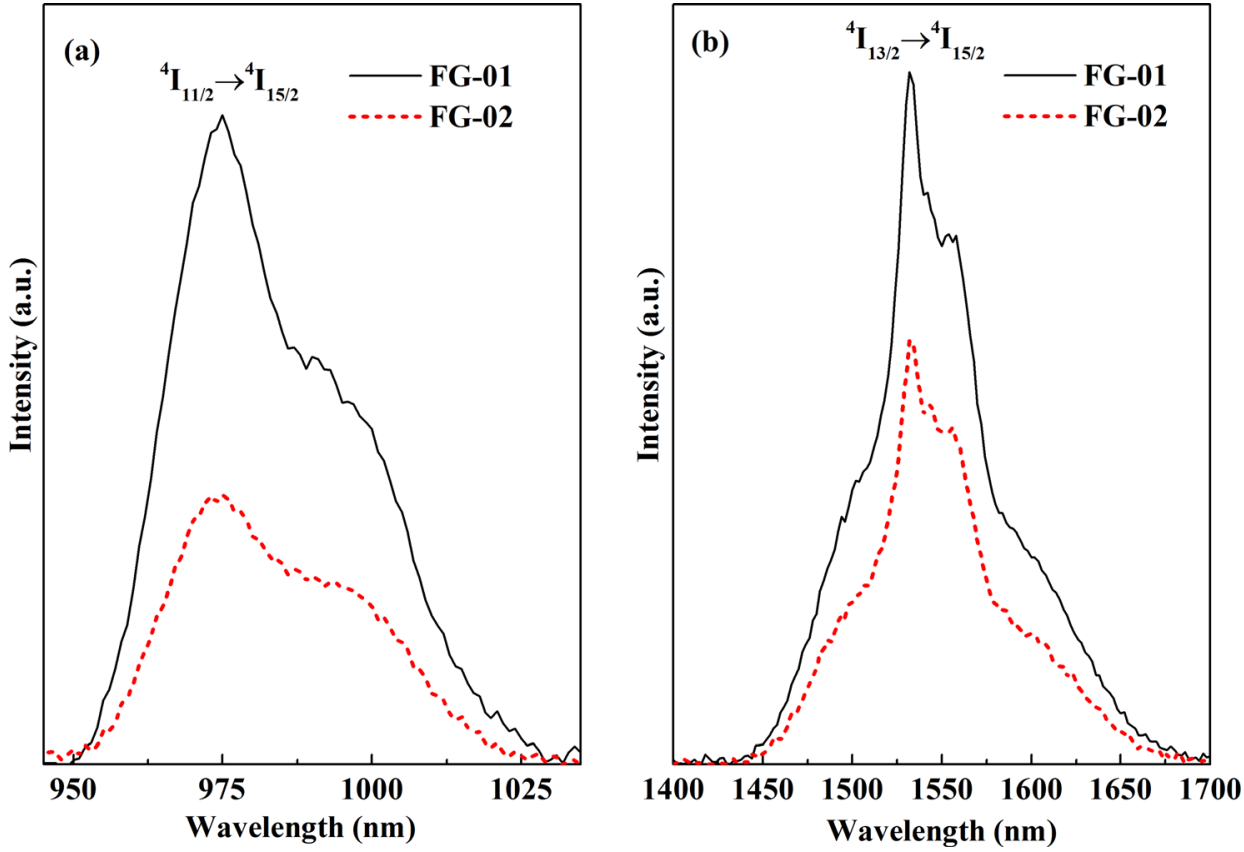

FIG. 3. (a) $975 \mathrm{~nm}$ and (b) $1.53 \mu \mathrm{m}$ emission spectra in $\mathrm{Er}^{3+}$ doped oxyfluogermanate glasses. and $\mathrm{R}_{\mathrm{c}}$ is the critical transfer distance defined as the donoracceptor separation for which the energy transfer rate is equal to the rate of intrinsic decay of the donors. Then, the energy transfer rate $\left(\mathrm{C}_{\mathrm{DA}}\right)$ can be given by

$$
C_{D A}=\frac{9 Q^{2}}{8 \pi N_{E r}^{2} \Gamma(1-3 / S) \tau_{0}} .
$$

Figs. 5(a) and 5(b) show fitting results of decay curves for $975 \mathrm{~nm}$ and $1.53 \mu \mathrm{m}$ emissions via I-H model. Relevant parameters were obtained as listed in Table III. The fitted results are reliable due to high values of Adj. R-Square. It is found that the $\mathrm{C}_{\mathrm{DA}}$ of $\mathrm{FG}-02$ sample is very similar to that of FG-01 sample for the ${ }^{4} \mathrm{I}_{11 / 2}$ level, whereas the $\mathrm{C}_{\mathrm{DA}}$ of FG-02 sample is larger than that of FG-01 sample for the ${ }^{4} \mathrm{I}_{13 / 2}$ level. It is indicated that FG-02 sample is more beneficial to the population inversion between ${ }^{4} \mathrm{I}_{11 / 2}$ and ${ }^{4} \mathrm{I}_{13 / 2}$ level due to its faster energy transfer rate of ${ }^{4} \mathrm{I}_{13 / 2}$ level compared with FG-01 sample. Thus, the $2.7 \mu \mathrm{m}$ emission of FG-02 sample is stronger than that of FG-01 sample.

Furthermore, the $\mathrm{S}$ values are determined to be 5.795-6.575, which are close to 6, indicating the dipoledipole interactions among $\mathrm{Er}^{3+}$ ions. The deviation from 6 could be attributed to the migration effect (or diffusion effect) among $\mathrm{Er}^{3+}$ ions. $^{30}$ In this case, Yokota-Tanimoto's model is used to estimate both energy transfer and diffusion processes by assuming that dipole-dipole interaction is a dominant mechanism. ${ }^{31}$ The expression is as follows:
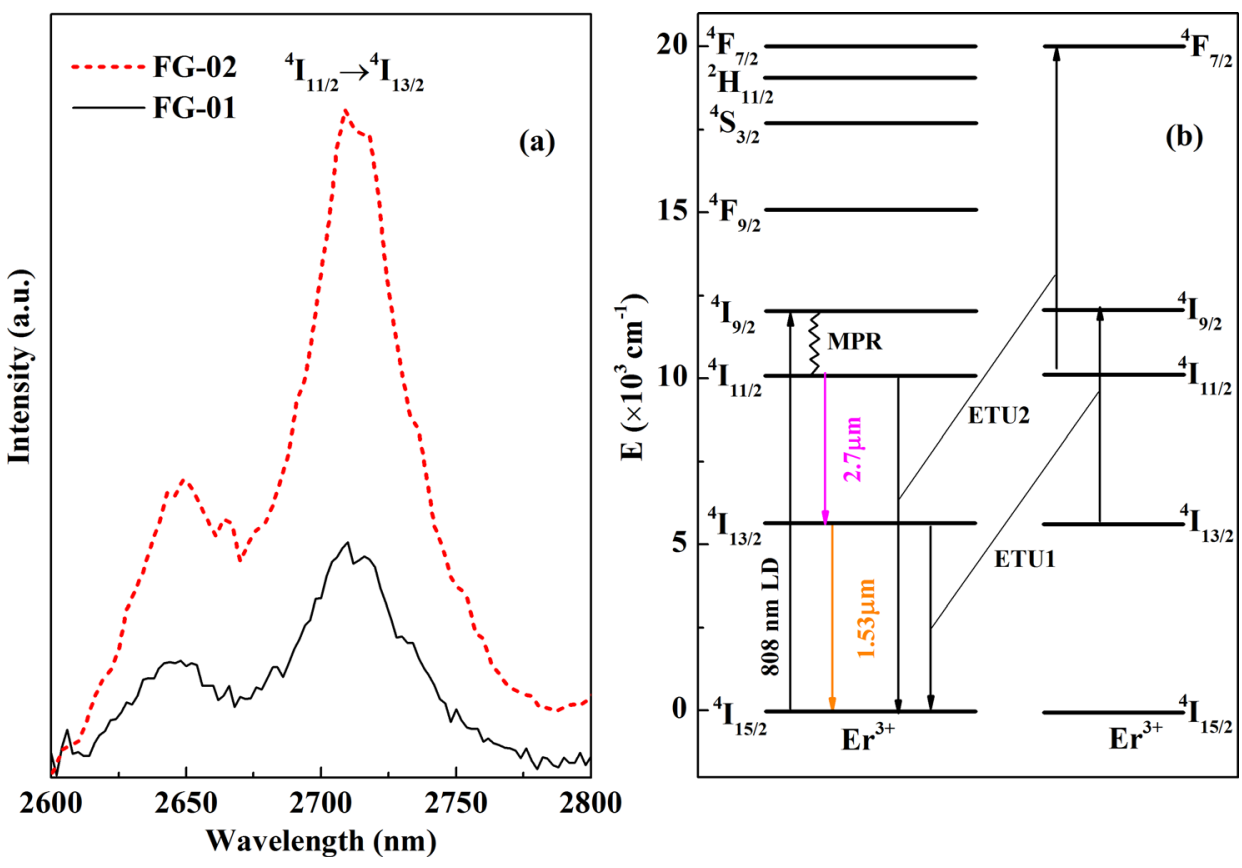

FIG. 4. (a) $2.7 \mu \mathrm{m}$ fluorescence spectra and (b) energy level diagram of $\mathrm{Er}^{3+}$ in oxyfluogermanate glasses. 


$$
I(t)=I_{0} \exp \left\{-\frac{t}{\tau_{0}}-\pi^{\frac{1}{2}} A\left(\frac{t}{\tau_{0}}\right)^{\frac{1}{2}}\left[\frac{1+10.87 B\left(\frac{t}{\tau_{0}}\right)^{\frac{2}{3}}+15.5 B^{2}\left(\frac{t}{\tau_{0}}\right)^{\frac{4}{3}}}{1+8.743 B\left(\frac{t}{\tau_{0}}\right)^{\frac{2}{3}}}\right]^{0.75}\right\}
$$

where $\mathrm{A}=\frac{4}{3} \pi N_{A} C_{D A}^{\frac{1}{2}}, \mathrm{~B}=\mathrm{D} C_{D A}^{-\frac{1}{3}} \cdot \mathrm{N}_{\mathrm{A}}$ is the concentration of $\mathrm{Er}^{3+}$ ions and $\mathrm{C}_{\mathrm{DA}}$ is the energy transfer microparameter of $\mathrm{Er}^{3+}$ ions. The fitted results of decay curves are shown in Figs. 5(c) and 5(d). The fitted parameters are also summarized in Table III. Good match between measured date and fitted curves signifies the validity and reliability of results. In Table III, one can find small changes of $C_{D A}$ values for ${ }^{4} I_{11 / 2}$ level in prepared samples. However, the $\mathrm{C}_{\mathrm{DA}}$ of ${ }^{4} \mathrm{I}_{13 / 2}$ level in FG-02 sample is much larger than that of FG-01 sample. High energy transfer rate of ${ }^{4} \mathrm{I}_{13 / 2}$ level is helpful to minimize the ions of this level and achieve population inversion between ${ }^{4} \mathrm{I}_{11 / 2}$ and ${ }^{4} \mathrm{I}_{13 / 2}$ levels. Results suggest that FG-02 sample is more beneficial for $2.7 \mu \mathrm{m}$ emissions.

\section{Cross sections and gain spectra}

To further understand $2.7 \mu \mathrm{m}$ emission properties, absorption and emission cross sections have been calculated and discussed. The absorption and emission cross sections can be obtained by Füchtbauer-Ladenburg equation ${ }^{32}$ and McCumber theory ${ }^{33}$
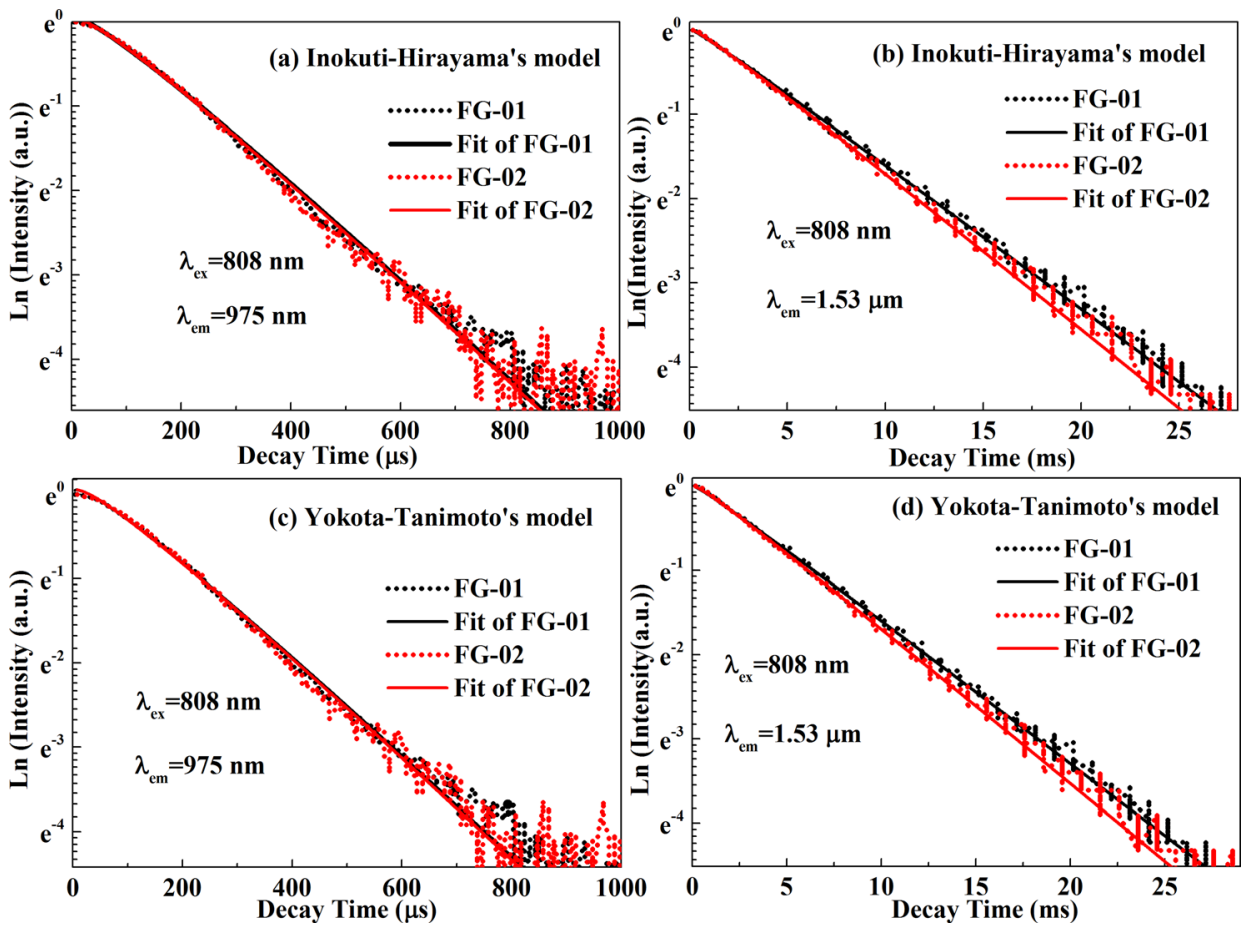

FIG. 5. Decay data and fitted curves of (a) $975 \mathrm{~nm}$ and (b) $1.53 \mu \mathrm{m}$ via Inokuti-Hirayama's model; (c) $975 \mathrm{~nm}$ and (d) $1.53 \mu \mathrm{m}$ via YokotaTanimoto's model.

TABLE III. The determined interaction factor S, energy transfer parameter Q and $\mathrm{C}_{\mathrm{DA}}$ fitted by Inokuti-Hirayama's model as well as the parameters A, B, and $\mathrm{C}_{\mathrm{DA}}$ fitted by Yokota-Tanimoto's model for $975 \mathrm{~nm}$ and $1.53 \mu \mathrm{m}$ emissions in $\mathrm{Er}^{3+}$ doped oxyfluogermanate glasses.

\begin{tabular}{|c|c|c|c|c|c|c|}
\hline \multirow[b]{2}{*}{ Sample } & \multicolumn{3}{|c|}{ Inokuti-Hirayama's model } & \multicolumn{3}{|c|}{ Yokota-Tanimoto's model } \\
\hline & Parameter & $975 \mathrm{~nm}$ & $1.53 \mu \mathrm{m}$ & Parameter & $975 \mathrm{~nm}$ & $1.53 \mu \mathrm{m}$ \\
\hline \multirow[t]{4}{*}{ FG-01 } & S & $5.795( \pm 0.055)$ & $6.575( \pm 0.206)$ & A & $0.253( \pm 0.002)$ & $0.071( \pm 0.002)$ \\
\hline & Q & $0.443( \pm 0.002)$ & $0.125( \pm 0.002)$ & B & $0.005( \pm 0.004)$ & $0.007( \pm 0.017)$ \\
\hline & $\mathrm{C}_{\mathrm{DA}}\left(\mathrm{cm}^{6} / \mathrm{s}\right)$ & $1.52 \times 10^{-39}$ & $3.32 \times 10^{-42}$ & $C_{D A}\left(\mathrm{~cm}^{6} / \mathrm{s}\right)$ & $2.09 \times 10^{-44}$ & $1.64 \times 10^{-45}$ \\
\hline & Adj. R-Square & 0.998 & 0.999 & Adj. R-Square & 0.998 & 0.999 \\
\hline \multirow[t]{4}{*}{ FG-02 } & S & $5.796(0.064)$ & $6.485( \pm 0.117)$ & A & $0.254( \pm 0.002)$ & $0.093( \pm 0.002)$ \\
\hline & Q & $0.444( \pm 0.002)$ & $0.165( \pm 0.001)$ & $\mathrm{B}$ & $0.0074( \pm 0.005)$ & $0.009( \pm 0.010)$ \\
\hline & $\mathrm{C}_{\mathrm{DA}}\left(\mathrm{cm}^{6} / \mathrm{s}\right)$ & $1.54 \times 10^{-39}$ & $3.65 \times 10^{-42}$ & $\mathrm{C}_{\mathrm{DA}}\left(\mathrm{cm}^{6} / \mathrm{s}\right)$ & $2.11 \times 10^{-44}$ & $2.83 \times 10^{-45}$ \\
\hline & Adj. R-Square & 0.997 & 0.999 & Adj. R-Square & 0.997 & 0.999 \\
\hline
\end{tabular}




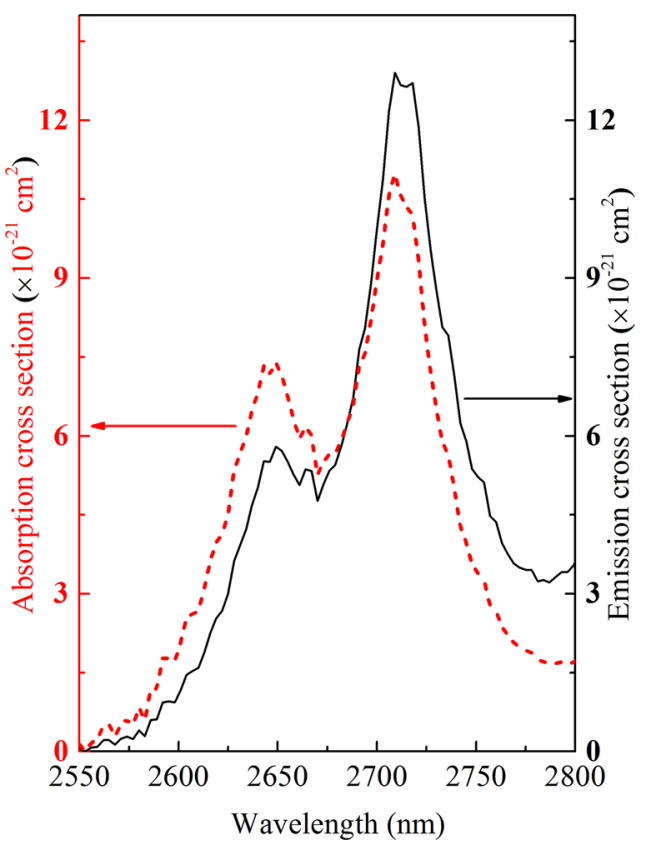

$$
\begin{gathered}
\sigma_{e m}(\lambda)=\frac{\lambda^{4} A_{r a d}}{8 \pi c n^{2}} \times \frac{\lambda I(\lambda)}{\int \lambda I(\lambda) d \lambda}, \\
\sigma_{e m}(\lambda)=\sigma_{a b s}(\lambda)\left(Z_{l} / Z_{u}\right) \exp [(\varepsilon-h \nu) / k T],
\end{gathered}
$$

where $\lambda$ is the wavelength, $A_{\text {rad }}$ is the spontaneous radiative transition probability, $\mathrm{I}(\lambda)$ is the fluorescence spectra intensity, $\mathrm{n}$ and $\mathrm{c}$ represent the refractive index and the speed of light, $\mathrm{Z}_{1}$ and $\mathrm{Z}_{\mathrm{u}}$ are partition functions of the lower and upper manifolds, respectively. $\varepsilon$ is the net free energy demanded to excite one $\mathrm{Er}^{3+}$ from the ${ }^{4} \mathrm{I}_{13 / 2}$ to ${ }^{4} \mathrm{I}_{11 / 2}$ state at the temperature of $\mathrm{T}$.

Fig. 6(a) displays the absorption and emission cross sections corresponding to $\mathrm{Er}^{3+}:{ }^{4} \mathrm{I}_{11 / 2} \rightarrow{ }^{4} \mathrm{I}_{13 / 2}$ transition in $\mathrm{Er}^{3+}$ doped oxyfluogermanate glass. It is shown that the peak absorption $\left(\sigma_{a b s}^{p}\right)$ and emission cross sections $\left(\sigma_{e m}^{p}\right)$ are $10.98 \times 10^{-21} \mathrm{~cm}^{2}$ and $12.90 \times 10^{-21} \mathrm{~cm}^{2}$, respectively. The prepared glass possesses much higher $\sigma_{e m}^{p}$ compared with ZBLAY glass $\left(9.16 \times 10^{-21} \mathrm{~cm}^{2}\right)^{9}$ and ZBLAN glass $\left(5.7 \times 10^{-21} \mathrm{~cm}^{2}\right) .{ }^{34}$ Higher emission cross section has larger opportunity to achieve laser action. ${ }^{22}$ Therefore, the prepared oxyfluogermanate glass would be an appropriate host to achieve efficient $2.7 \mu \mathrm{m}$ laser using an $808 \mathrm{~nm}$ laser diode.

Gain coefficient is another characteristic parameter to evaluate $2.7 \mu \mathrm{m}$ emission properties quantitatively. The wavelength dependent gain coefficient is calculated in detail as a function of population inversion for the upper laser level on the basis of the $\sigma_{\mathrm{abs}}$ and $\sigma_{\mathrm{em}}$. The room temperature gain coefficient $(\mathrm{G}(\lambda, \mathrm{P}))$ can be simply denoted as

$$
G(\lambda, P)=N\left[P \sigma_{e m}(\lambda)-(1-P) \sigma_{a b s}(\lambda)\right],
$$

where $\mathrm{N}$ is the total concentration of $\mathrm{Er}^{3+}$ and $\mathrm{P}$ is the population inversion given by the ratio between the population of $\mathrm{Er}^{3+}:{ }^{4} \mathrm{I}_{11 / 2}$ level and the total $\mathrm{Er}^{3+}$ concentration.

The calculated gain spectra of oxyfluogermanate glass are shown in Fig. 6(b). It can be observed that the gain
FIG. 6. (a) Calculated absorption and emission cross sections (b) gain spectra for ${ }^{4} \mathrm{I}_{11 / 2} \rightarrow{ }^{4} \mathrm{I}_{13 / 2}$ transition in $\mathrm{Er}^{3+}$ doped oxyfluogermanate glass. coefficient is as high as $5.38 \mathrm{~cm}^{-1}$, which is significantly larger than those of fluorotellurite $\left(2.16 \mathrm{~cm}^{-1}\right)^{35}$ and ZBLAN glasses $\left(0.6 \mathrm{~cm}^{-1}\right) .{ }^{34}$ Furthermore, the positive gain can be obtained in the range of $2685-2800 \mathrm{~nm}$ when $\mathrm{P}>0.4$, similar to the case of ZBLAN. ${ }^{14}$

In addition, based on the theory derived by Giles and Desurvire for modeling fiber amplifiers, ${ }^{36}$ the gain per unit length $g$ at frequency $\nu$ and position $\mathrm{z}$ can be expressed as ${ }^{37}$

$$
g_{v}(z)=N_{0} \Gamma_{v}\left\{\sigma_{e v} n_{e}(z)-\sigma_{a v}\left(1-n_{e}(z)\right)\right\},
$$

where $\mathrm{N}_{0}$ is the total rare-earth-ion and $\Gamma_{\nu}$ is the normalized spatial overlap between the propagating mode and the rareearth concentration profile. $\sigma_{\mathrm{av}}$ and $\sigma_{\mathrm{ev}}$ are the wavelength dependent absorption and emission cross-sections of $\mathrm{Er}^{3+}$ ions, respectively. $\mathrm{n}_{\mathrm{e}}$ is the normalized excited-state population density. Equation (9) indicates that the maximum gain per unit length $g_{v}$ is mainly determined by the emission and absorption cross-sections as well as the population inversion of the active ions. Considering a general case with a spatial overlap $\Gamma_{\nu}$ of $100 \%$ and normalized excited-state population density $\mathrm{n}_{\mathrm{e}}$ of $80 \%$, the maximum gain per unit length at 2.7 $\mu \mathrm{m}$ could be as high as $3.3 \mathrm{~dB} / \mathrm{cm}$ in a $1 \mathrm{~mol} . \% \mathrm{Er}^{3+}$-doped FG-02. These indicate that the prepared glass has high gain and low pumping threshold for the $2.7 \mu \mathrm{m}$ laser action.

\section{CONCLUSIONS}

Oxyfluogermanate glasses with good thermal properties have been prepared. Furthermore, $2.7 \mu$ m fluorescence properties and energy transfer mechanism have been investigated under the excitation of an $808 \mathrm{~nm}$ laser diode. The prepared sample possesses high spontaneous radiative transition probability $\left(32.64 \mathrm{~s}^{-1}\right)$, large emission cross section $(12.90$ $\times 10^{-21} \mathrm{~cm}^{2}$ ), and good gain performance for $\mathrm{Er}^{3+}:{ }^{4} \mathrm{I}_{11 / 2}$ $\rightarrow{ }^{4} \mathrm{I}_{13 / 2}$ transition. The decay data of ${ }^{4} \mathrm{I}_{11 / 2}$ and ${ }^{4} \mathrm{I}_{13 / 2}$ levels have been measured and their energy transfer parameters have been determined by fitting decay curves to Inokuti- 
Hirayama and Yokota-Tanimoto's models, respectively. It is found that dipole-dipole interaction is dominant mechanism among $\mathrm{Er}^{3+}$ ions via Inokuti-Hirayama's model. It is indicated that the oxyfluogermanate glass is an attractive laser material for mid-infrared applications.

\section{ACKNOWLEDGMENTS}

This research was financially supported by the Chinese National Natural Science Foundation (Nos. 51172252, 51372235, 61308090, and 51272243) and Zhejiang Provincial Natural Science Foundation of China (Nos. LR14E020003, LY13F050003, and LY14E020007).

${ }^{1}$ S. D. Jackson, Appl. Phys. Lett. 83, 1316 (2003).

${ }^{2}$ W. Tianshu, W. Yizhen, H. Kai, Z. Peng, J. Qingsong, and J. Huilin, Microwave Opt. Technol. Lett. 56, 848 (2014).

${ }^{3}$ G. S. Henderson and M. E. Fleet, J. Non-Cryst. Solids 134, 259 (1991).

${ }^{4}$ F. Tong, W. P. Risk, R. M. MacFarlane, and W. Lenth, Electronics Letters (Institution of Engineering and Technology, 1989), Vol. 25, p. 1389.

${ }^{5}$ L. Gomes and S. D. Jackson, J. Opt. Soc. Am. B 30, 1410 (2013).

${ }^{6}$ X. Zhuang, H. Xia, H. Hu, J. Hu, P. Wang, J. Peng, Y. Zhang, H. Jiang, and B. Chen, Mater. Sci. Eng., B 178, 326 (2013).

${ }^{7}$ A. Sennaroglu, Y. H. Tsang, A. E. El-Taher, T. A. King, K.-P. Chang, and S. D. Jackson, Proc. of SPIE 6190, 61900J (2006).

${ }^{8}$ G. Zhao, Y. Tian, H. Fan, J. Zhang, and L. Hu, Chin Opt. Lett. 10, 091601 (2012).

${ }^{9}$ Y. Tian, R. Xu, L. Hu, and J. Zhang, Opt. Mater. 34, 308 (2011).

${ }^{10}$ M. Liao, H. Sun, L. Wen, Y. Fang, and L. Hu, Mater. Chem. Phys. 98, 154 (2006).

${ }^{11}$ Y. Guo, Y. Ma, F. Huang, Y. Peng, L. Zhang, and J. Zhang, Spectrochim. Acta, Part A 111, 150 (2013).

${ }^{12}$ R. Xu, Y. Tian, L. Hu, and J. Zhang, Opt. Lett. 36, 1173 (2011).

${ }^{13}$ D. J. Coleman, S. D. Jackson, P. S. Golding, T. A. King, S. H. Park, Y. B. Shin, and J. Heo, in Heavy Metal Oxide and Chalcogenide Glasses as New Hosts for $\mathrm{Er}^{3+}$ and $\mathrm{Er}^{3+} / \mathrm{Pr}^{3+}$ Mid-IR Fiber Lasers (Optical Society of America, Davos, Switzerland, 2000), p. MB10.

${ }^{14}$ F. Huang, Y. Ma, W. Li, X. Liu, L. Hu, and D. Chen, Sci. Rep. 4, 3607 (2014).
${ }^{15}$ D. Faucher, M. Bernier, G. Androz, N. Caron, and R. Vallée, Opt. Lett. 36, 1104 (2011).

${ }^{16}$ D. D. Hudson, R. J. Williams, M. J. Withford, and S. D. Jackson, Opt. Lett. 38, 2388 (2013).

${ }^{17}$ Y. H. Tsang, A. E. El-Taher, T. A. King, and S. D. Jackson, Opt. Express 14, 678 (2006).

${ }^{18}$ R. Xu, Y. Tian, L. Hu, and J. Zhang, J. Appl. Phys. 111, 033524 (2012).

${ }^{19}$ G. Cao, F. Lin, H. Hu, and F. Gan, J. Non-Cryst. Solids 326-327, 170 (2003).

${ }^{20}$ X. Li, X. Liu, L. Zhang, L. Hu, and J. Zhang, Chin Opt. Lett. 11, 121601 (2013).

${ }^{21}$ J. Hu, H. Xia, H. Hu, X. Zhuang, Y. Zhang, H. Jiang, and B. Chen, Mater. Res. Bull. 48, 2604 (2013).

${ }^{22}$ Y. Tian, R. Xu, L. Hu, and J. Zhang, J. Quantum Spectrosc. Radiat. Transfer 113, 87 (2012).

${ }^{23}$ B. Judd, Phys. Rev. 127, 750 (1962).

${ }^{24}$ G. S. Ofelt, J. Chem. Phys. 37, 511 (1962).

${ }^{25}$ Y. V. Orlovskii, T. T. Basiev, K. K. Pukhov, O. K. Alimov, N. A. Glushkov, and V. A. Konyushkin, Opt. Mater. 32, 599 (2010).

${ }^{26}$ X. Li, Q. Nie, S. Dai, T. Xu, L. Lu, and X. Zhang, J. Alloys Compd. 454, 510 (2008).

${ }^{27}$ J. Fan, Y. Fan, Y. Yang, D. Chen, L. Calveza, X. Zhang, and L. Zhang, J. Non-Cryst. Solids 357, 2431 (2011).

${ }^{28}$ H. Lin, D. Chen, Y. Yu, A. Yang, and Y. Wang, Opt. Lett. 36, 1815 (2011).

${ }^{29}$ J. Heo, Y. B. Shin, and J. N. Jang, Appl. Opt. 34, 4284 (1995).

${ }^{30}$ K.-S. Sohn, Y. Y. Choi, and H. D. Park, J. Electrochem. Soc. 147, 1988 (2000).

${ }^{31}$ V. Moizan, V. Nazabal, J. Troles, P. Houizot, J.-L. Adam, J.-L. Doualan, R. Moncorge, F. Smektala, G. Gadret, S. Pitois, and G. Canat, Opt. Mater. 31, 39 (2008).

${ }^{32}$ S. A. Payne, L. Chase, L. K. Smith, W. L. Kway, and W. F. Krupke, IEEE J. Quantum Electron. 28, 2619 (1992).

${ }^{33}$ D. McCumber, Phys. Rev. 136, A954 (1964).

${ }^{34}$ B. Wang, L. Cheng, H. Zhong, J. Sun, Y. Tian, X. Zhang, and B. Chen, Opt. Mater. 31, 1658 (2009).

${ }^{35}$ Y. Ma, Y. Guo, F. Huang, Y. Peng, L. Hu, and J. Zhang, J. Non-Cryst. Solids 369, 23 (2013).

${ }^{36}$ C. R. Giles and E. Desurvire, J. Lightwave Technol. 9(2), 271-283 (1991).

${ }^{37}$ J. L. Wagener, D. G. Falquier, M. J. F. Digonnet, and H. J. Shaw, J. Lightwave Technol. 16(2), 200-206 (1998). 